\title{
Evaluation of Pull Production Control Strategies Under Uncertainty: An Integrated Fuzzy Ahp-Topsis Approach
}

\author{
Aydin M. Torkabadi iD, Rene V. Mayorga iD \\ University of Regina (Canada) \\ torkabam@uregina.ca, Rene.Mayorga@uregina.ca
}

Received: November 2017

Accepted: February 2018

\begin{abstract}
:
Purpose: Just-In-Time (JIT) production has continuously been considered by industrial practitioners and researchers as a leading strategy for the yet popular Lean production. Pull Production Control Policies (PPCPs) are the major enablers of JIT that locally control the level of inventory by authorizing the production in each station. Aiming to improve the PPCPs, three authorization mechanisms: Kanban, constant-work-in-process (ConWIP), and a hybrid system, are evaluated by considering uncertainty.
\end{abstract}

Design/methodology/approach: Multi-Criteria Decision Making (MCDM) methods are successful in evaluating alternatives with respect to several objectives. The proposed approach of this study applies the fuzzy set theory together with an integrated Analytical Hierarchy Process (AHP) and a Technique for Order Performance by Similarity to Ideal Solution (TOPSIS) method.

Findings: The study finds that hybrid Kanban-ConWIP pull production control policies have a better performance in controlling the studied multi-layer multi-stage manufacturing and assembly system.

Practical implications: To examine the approach a real case from automobile electro-mechanical part production industry is studied. The production system consists of multiple levels of manufacturing, feeding a multi-stage assembly line with stochastic processing times to satisfy the changing demand.

Originality/value: This study proposes the integrated Kanban-ConWIP hybrid pull control policies and implements several alternatives on a multi-stage and multi-layer manufacturing and assembly production system. An integrated Fuzzy AHP TOPSIS method is developed to evaluate the alternatives with respect to several JIT criteria.

Keywords: just-in-time manufacturing, kanban system, hybrid control policy, multi-criteria decision making, fuzzy topsis

\section{Introduction}

The success of Lean and just-in-time (JIT) manufacturing was praised by both industry practitioners and academic researchers (Krafcik, 1988) (Womack, Jones \& Roos, 1990). The extensive recent research and case studies in JIT proves that yet this methodology is popular in both academia and industry. Pull production control policies (PPCPs) are the major enablers for JIT manufacturing. The goal of PPCP is to maintain a balance between the inventory level and availability of products to fulfill the demand.

Since the introduction of the first PPCP, Kanban system by Ohno (1988) in Toyota Production System (TPS), researchers developed, optimized, and introduced several Kanban systems. However, the systems were 
implemented for specific conditions and environments (Thürer, Stevenson \& Protzman, 2016). Comparisons of different PPCPs implemented for the same production systems also show contradictory results. This issue motivates this study to investigate the performance of the systems and address the ambiguity resulting from production conditions.

Researchers argued that despite the success of Traditional Kanban System in Toyota, this system is not adequate in further production conditions. This issue created an opportunity for researchers advocating newer strategies. The constant work-in-process (ConWIP) system developed by Spearman, Woodruff and Hopp (1990) was suggested as an alternative to Traditional Kanban System. ConWIP, similar to Kanban System, uses Kanban card/signal to control the Work-In-Process (WIP), but simply considers one set of Kanbans that circulate in the entire system (Framinan, Ruiz-Usano \& Leisten, 2001; Thürer, Fernandes, Stevenson \& Ting Qu, 2017).

In a multi-stage production and manufacturing system, by designing various combinations of Kanban and ConWIP control policies, hybrid production control policies can be defined. Hybrid PPCPs offer the advantages of both Kanban and ConWIP systems (Torkabadi \& Mayorga, 2017). This paper contributes to the research by proposing a comprehensive framework to develop, combine, compare, and select the superior PPCP considering the uncertainty.

The implementation of PPCSs is reported in various industries through case studies. Continuing popularity of pull strategies among industry practitioners is apparent from the cases. The literature shows the adaptability PPCSs in industries with different environments. The case studies report the implementation of policies in environments with automated automobile assembly lines to job shops (Ni \& Wang, 2015; Gilland, 2002; Parakash \& Chin, 2014; Farnoush \& Wiktorson, 2013; Slomp, Bokhorst \& Germs, 2009; Yang, Fu \& Yang, 2007). Reviewing the cases, the reported environmental conditions and barriers can highlight the areas of improvement in PPCS research. This study considers a case from automobile electro mechanical part industry. The case is studied to experiment the proposed framework in this research.

Dissimilar properties of production and assembly systems make the comparison among pull production strategies, such as Kanban and ConWIP, vary in results. This issue creates a demand for further studies. It is important to clarify the studied production system's properties, such as single or multi-level, and the measuring criteria that are considered for analyzing the pull production policies. Sharma and Agrawal (2012) considered a single level serial production system to compare Kanban, ConWIP and a hybrid production control policy. Sato and Khojasteh-Ghamari (2012) developed a framework to compare Kanban and ConWIP strategies in a multi-stage and multi-level production and assembly system. In these systems multi-stage serial production lines feed the assembly line. This study compares Kanban, ConWIP and multiple developed hybrid policies in a multi-stage and multi-level production and assembly system. Xanthopoulos and Koulouriotis (2014) considered mean WIP and mean backorders to compare pull production policies in a multi-level and multi-stage production and assembly line. Literature suggests that WIP level is consistently the most popular measurement criteria to evaluate the systems. For comparing Kanban, ConWIP and hybrid policies this study considers the following measuring criteria: WIP level, number of backorders (BO), lead time (LT), and waiting time (WT). Therefore, the question in this study is which among Kanban, ConWIP and proposed hybrid production control policies is superior in a multi-stage and multi-layer production and assembly system with regards to the measurement criteria.

\section{Literature Review}

The Kanban strategy is inspired from the work of Ohno (1988) and was extensively studied and implemented by researchers and practitioners since the popularity of JIT (Krafcik, 1988). Its adoptability for various work environments is a reason for continues attention to this strategy (Thürer et al., 2016). In this system the production level in between two stations is limited by a number of authorization cards (Monden, 2011). In a recent study (Thürer et al. 2017) the difference between WIP Kanbans and operation Kanbans was clerified. The study revealed that most researchers considered WIP Kanbans in designing and developing their PPCP. The WIP Kanban is the authorization from the proceeding buffer station meaning that the buffered part was used and that the production station can start the process to fill the buffer. Therefore, it can be concluded that WIP kanabn circulates in between the buffer station and the production station when there is a demand to buffer. On the other hand, the operation 
Kanban circulates in between the production stations when there is an actual demand to process (Thürer et al., 2017).

Similar to Kanban PPCP, ConWIP uses the Kanban authorisation cards to limit the WIP level in the production system. The CONWIP control system proposed by Spearman et al. (1990) uses a single card/signal type to control the total amount of WIP in the line. But researchers costomized and designed ConWIP systems with multiple card types and card loops (Ang, 2015).

Selecting the criteria to measure the performance of systems is important to conduct a meaningful comparison. The measurement criteria are the objectives of the system to achieve the overall goal of determining the best strategy. Researchers considered various objective functions. Cost reduction is widely considered by researchers since different objectives can be translated to a cost-based objective (Prajapat \& Tiwari, 2017). Studies that consider cost-based objectives discuss that other objectives result in either increased sales or reduced production expenses and overhead. Therefore, the two cost-based approaches followed by researchers are maximization of revenue and minimization of expenses. Minimizing the cost was considered (Marsh, Jonik, Lanham, Cheung, Newnes \& Mileham, 2010; Stratman, Roth \& Gilland, 2004; Lu \& Sundaram, 2002; Cochran \& Kaylani, 2008) by identifying the criteria that leads to higher production costs like: inventory, backlog, labor, testing, inspection, defect, and high lead time. The profit from sales and operation per time unit are examples of measuring criteria that are aimed to be maximized (Xanthopoulos \& Koulouriotis, 2014).

Work-in-process and system throughput remain the most popular measuring criteria among researchers who study pull production control policies. The little's law (Little, 1961), that states the relationship between the average number of orders in the system, arrival rate, and the lead time, was used by Spearman et al. (1990) to show the tradeoff between WIP level and throughput. Khojasteh-Ghamari (2012) considered WIP and throughput to compare the ConWIP system with Kanban in a multi-level production and assembly line. In their literature review, Prajapat \& Tiwari (2017), reported that System throughput is primary objective by many researchers who considered it directly (Ferreira, Gómez, Lourido, Quintas \& Tjahjono, 2012; Han, Zhou, Bras, McGinnis, Carmichael \& Newcomb, 2003; Kouikoglou, 2000; Koulouriotis, Xanthopoulos \& Tourassis, 2010; Manns \& Elmaraghy, 2009; Mendes, Ramos, Simaria \& Vilarinho, 2005) or indirectly via a measure that is closely related to throughput (Yu, Duffy, McGinley \& Rowland, 2006; Neira Duenas, Lamas Rodríguez, Duro \& García Del Valle, 2007; Ferreira et al., 2012; Aguirre, Muller, Seffino \& Méndez, 2008; Yang, Bukkapatnam \& Barajas, 2013). Reducing the work-in-process is aimed by lean production and is considered by researchers (Otamendi, 2011; Pradhan \& Damodaran, 2009; Yang et al., 2013; Zeng, Wong \& Leung, 2012) The importance of this criteria comes from the fact that designating the number of Kanbans and designing the circulation of loops directly impacts the level of work-in-process.

The time-based nature of both the discrete event computer simulation (DECS) and initiatives of lean manufacturing resulted in popularity of time-based objectives among researchers. Reducing the lead time is aimed by JIT as a major objective. The suitability of DECS, as a method based on time events, conventionally makes designing time-based objectives popular. Prajapat and Tiwari (2017) found that time-based objectives are the most popular criteria among research applying DECS for optimizing the manufacturing and assembly systems. Sharma and Agrawal (2012) and Kibira and McLean (2002) considered lead time in their studies. Specific characteristics of the production system are another issue that grounds uncertainty in comparing PPCPs. Some studies are distinguished by considering a production system with a high product mix. The variation of job sequencing that distinct orders need to go through, adds complexity to the design of the control policy. The configuration of the production system is another property that is considered by studies. These studies consider a production system with multiple stages or multiple levels, or both. A system of multiple production series that feed an assembly line is an example of such systems. The variation of job sequencing that distinct orders need to go through, adds complexity to the design of the PPCP. Reviewing the literature, we found that many researchers focused on uncertainty in production systems. Studying PPCPs in environments with variable processing rate, demand, and rate of failure is the focus of many studies.

Since various performance measures are considered to evaluate the systems controlled by different strategies, MCDM techniques are effective methods. The work of Andijani (1998) is one of the early examples of applying 
Analytic Hierarchy Process to select the best Kanban allocation for a pull production control strategy. The study aimed to achieve the best results with respect to average work-in-process, flow time and throughput. Simulation technique was used to determine the Kanban allocation, where the total number of Kanbans is unchanging. Sharma and Agrawalb (2009) compared the performance of Kanban, CONWIP and Hybrid production control systems for varying demands and multiple criteria using Analytical Hierarchy Process. Similarly, Lavoie, Gharbi and Kenné (2010) compared Kanban, ConWIP and Hybrid Production control systems for a serial production with respect to machine unreliability. Their study applied simulation techniques together with design-of-experiment methods to compare the three alternatives based on measurement criteria. Hou and Hu (2011) applied a multiobjective genetic algorithm to determine the Kanban sizes. They generated results from simulation and used a regression model to optimize the mean throughput and mean work-in-process. The comparison of Push, Kanban, ConWIP and drum-buffer-rope production control systems was done by $\mathrm{Ng}$, Bernedixen and Syberfeldt (2012). They applied an evolutionary multi-objective algorithm by considering two objectives. Xanthopoulos and Koulouriotis (2014) compared Kanban, ConWIP, Base Stock, and hybrid systems for a serial multi-stage system. They used discrete-event simulation and design of experiment techniques to minimize the mean work-in-process and mean number of backorders.

Since various performance measures are considered to evaluate the systems controlled by different strategies, MCDM techniques are effective methods. To resolve the uncertainty the fuzzy sets theory was considered in MCDM methods. Sharma and Agrawal (2012), to deal with uncertainty in the comparison of pull production policies, applied fuzzy techniques. They considered a multi-stage production line with two products assuming that the first product is produced in the first manufacturing period and the second product is made during the second period. They used computer simulation to find the performance of Kanban, ConWIP, and hybrid systems with respect to 5 criteria. The comparison is based on service level, throughput, WIP level, lost demand, and machine utilization.

Researchers applied various methodologies to study the performance of PPCPs. Generally, these methods can be classified into two categories: simulation and analytical methods. DECS remains one of the most popular techniques. Due to the discrete nature of orders, as the main entity in the studied production systems, DECS is found to be an effective solution.

\section{Methodology}

\subsection{Fuzzy Set Theory}

The fuzzy set theory as presented by Zadeh (1965) is a mathematical method to model the vagueness and ambiguity in human cognition. The degree of membership, which determines the membership of an element in a fuzzy set, is the key idea in fuzzy set theory (Zimmermann, 1996). Mapping the crisp inputs in a set of intervals that cover all the possible input values is performed by the help of membership functions. Then a degree of membership is assigned to illustrate the level of belongingness of the crisp input to the interval in which it was mapped. Therefore, the degree of membership specifies that to what level an input value can fit in a set. The membership degree most commonly ranges from zero to one. An element with a zero-membership degree of a certain set has no relation to that set. On the other hand, if the degree of membership is 1 it shows that the element definitely belongs to that set and has total membership. If an element has a degree of membership that is between 0 and 1 it partially belongs to the fuzzy set. The closer the membership degree is to one, the stronger the element belongs to the set. For a fuzzy set, usually, a membership function can be presented that gives the degree of membership for an element. Therefore, a fuzzy set has elements with varying levels of membership.

For the pair-wise comparison of measurement criteria and alternatives, this study uses triangular fuzzy numbers, $\tilde{1}$ to $\widetilde{9}$. The fuzzy numbers are used to capture the uncertainty and triangular fuzzy numbers are argued to be a suitable and understandable representative for this comparison (Table 1 and Figure 1).

A triangular fuzzy number in this study is denoted as $\widetilde{M}=(l, m, u)$, where $l$ is the lower limit, $m$ is the median value, and $u$ is the upper limit. The membership function can be defined by the following expression (Chang Horng $\&$ Lin, 2009). 


$$
\mu_{F}(x)=\left\{\begin{array}{cc}
0, & x<l \\
(x-l) /(m-l), & l \leq x \leq m, \\
(u-x) /(u-m), & m \leq x \leq u, \\
0, & x>u .
\end{array}\right.
$$

Alternatively, by defining the interval of confidence level $\alpha$, the triangular fuzzy number can be described as:

$$
\forall \alpha \in[0,1] \quad \tilde{A}_{\alpha}=\left[l^{\alpha}, u^{\alpha}\right]=[(m-l) \alpha+l,-(u-m) \alpha+u]
$$

Also, suppose $a=\left(a_{1}, a_{2}, a_{3}\right)$ and $\mathrm{b}=\left(b_{1}, b_{2}, b_{3}\right)$ are two TFNs, the distance between them is calculated as:

$$
d v(\tilde{a}, \tilde{b})=\sqrt{\frac{1}{3}\left[\left(a_{1}-b_{1}\right)^{2}+\left(a_{2}-b_{2}\right)^{2}+\left(a_{3}-b_{3}\right)^{2}\right]}
$$

\begin{tabular}{|c|c|c|c|}
\hline Intensity of importance & Fuzzy number & Judgment or preference & Function \\
\hline 1 & $\tilde{1}$ & Equally important & $(1,1,2)$ \\
\hline 3 & $\tilde{3}$ & Slightly more important & $(2,3,4)$ \\
\hline 5 & $\tilde{5}$ & Moderately more important & $(4,5,6)$ \\
\hline 7 & $\tilde{\mathbf{7}}$ & Strongly more important & $(6,7,8)$ \\
\hline 9 & $\tilde{\mathbf{9}}$ & Extremely more important & $(8,9,10)$ \\
\hline
\end{tabular}

Table 1. Scale of relative importance used in the pair-wise comparison matrix. (Pourjavad \& Shirouyehzad, 2014)

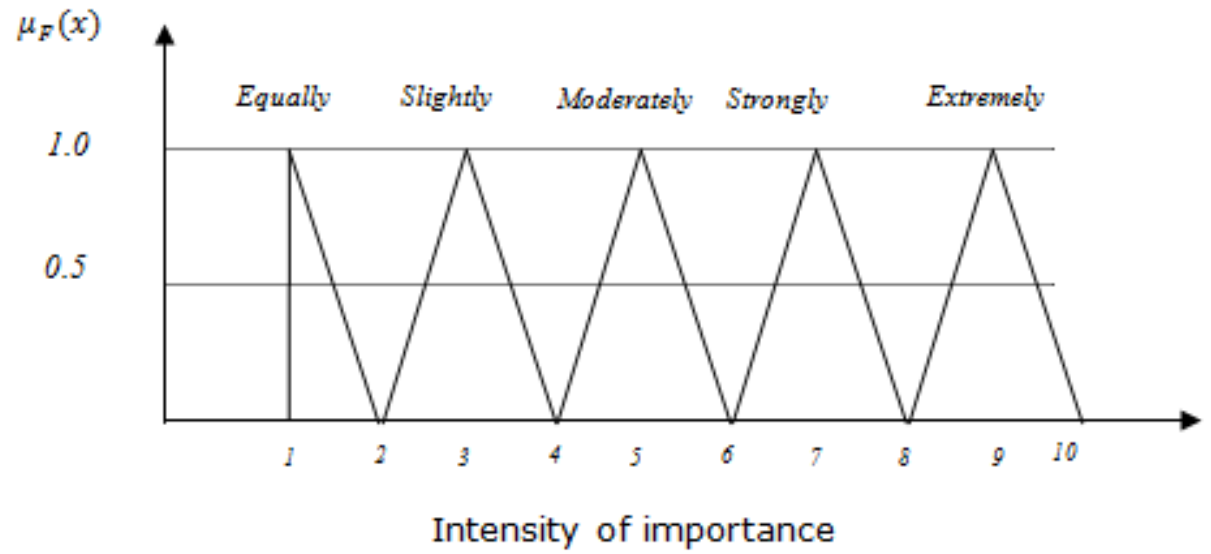

Figure 1. Fuzzy membership function for linguistic values

\subsection{Fuzzy AHP}

Analytical hierarchy process (Saaty, 1980) is a quantitative method to facilitate finding solutions for problems that can be constructed hierarchically through levels of multiple goals, criteria, and alternatives. Considering multiple criteria for achieving a solution is the biggest advantage of this method. The method is very effective for ranking multiple alternatives based on multiple objectives. However, the method has some limitations. The first limitation is that AHP is developed to deal with crisp values and numbers. Second, the judgments and comparisons are made in an unbalanced scale that is hard to evaluate. The third limitation of AHP is its shortage to deal with the uncertainty. The vagueness is a naturally associated with human comparison in AHP process, but there are no mechanisms to deal with the ambiguity in this method. As a result, the forth limitation is that the rankings are not precise. Finally, the results can be greatly affected by the mindset, preference and decision maker's judgment. In response, the ideas of fuzzy set theory are included in the AHP 
method to improve the process (Chamodrakas, Batis \& Martakos, 2010, Pourjavad, Shirouyehzad \& Shahin, 2013).

The combination of fuzzy set theory and MCDM methods in real world case studies enriched the literature with applicable frameworks (Onut, Kara, \& Isik, 2009). The methodological framework of Ayag (2005) for fuzzy AHP method is followed by this study. First, performance scores are defined and represented by linguistic terms. The linguistic terms show the relative significance of comparisons. Second the criteria are compared. For this purpose, pair-wise comparison of elements in the same level of hierarchy is conducted to display the relative importance of factors. The fuzzy comparison matrices use triangular fuzzy numbers $(\tilde{1}, \tilde{3}, \tilde{5}, \tilde{7}, \tilde{9})$ to display the importance of factors in every level of hierarchy.

The fuzzy AHP method which is used in this study is based on methodology steps of Ayag (2005). In the first step, the performance scores are compared. Linguistic terms are applied to display the relative strength of each pair of elements in the same hierarchy. Then in the second step, the fuzzy comparison matrices are constructed. Triangular fuzzy numbers $(\tilde{1}, \tilde{3}, \tilde{5}, \widetilde{7}, \widetilde{9})$ are used to indicate the relative strength of each pair of elements in the same hierarchy. The fuzzy judgment matrix $\tilde{A}$ is displayed as:

$$
\tilde{A}=\left[\begin{array}{ccccc}
1 & \tilde{a}_{12} & \cdots & \cdots & \tilde{a}_{1 n} \\
\tilde{a}_{21} & 1 & \cdots & \cdots & \tilde{a}_{2 n} \\
\vdots & \vdots & \vdots & \vdots & \vdots \\
\tilde{a}_{n 1} & \tilde{a}_{12} & \cdots & \cdots & 1
\end{array}\right]
$$

Where for $i$ equal to $j$ we have $\tilde{a}_{i j}=1$, otherwise $\tilde{a}_{i j}=\tilde{1}, \tilde{3}, \tilde{5}, \tilde{7}, \tilde{9}$ or $\tilde{1}^{-1}, \tilde{3}^{-1}, \tilde{5}^{-1}, \tilde{7}^{-1}, \tilde{9}^{-1}$. In the third step, the fuzzy eigenvalues are solved. A fuzzy eigenvalue, $\tilde{\lambda}$, is a fuzzy number solution to:

$$
\tilde{A} \tilde{x}=\tilde{\lambda} \tilde{x}
$$

Where the largest eigenvalue of $\tilde{A}$ is considered to be $\tilde{\lambda}_{\max } . \tilde{x}$ is a non-zero $n \times 1$, fuzzy vector and it includes fuzzy number $x_{i}$. by applying fuzzy multiplication and addition rules, the equation $\tilde{A} \tilde{x}=\tilde{\lambda} \tilde{x}$ would be equivalent to:

$$
\left[a_{i 1 l}^{\alpha} x_{1 l}^{\alpha}, a_{i 1 u}^{\alpha} x_{1 u}^{\alpha}\right] \oplus \ldots . \oplus\left[a_{i n l}^{\alpha} x_{n l}^{\alpha}, a_{i n u}^{\alpha} x_{n u}^{\alpha}\right]=\left[\lambda x_{i l}^{\alpha}, \lambda x_{i u}^{\alpha}\right]
$$

Where,

$$
\begin{gathered}
\tilde{A}=\left[a_{i j}^{\alpha}\right], \tilde{x}^{t}=\left(\tilde{x}_{1}, \ldots \ldots \ldots \tilde{x}_{n}\right), \\
\tilde{a}_{i j}^{\alpha}=\left[a_{i j l}^{\alpha}, a_{i j u}^{\alpha}\right], \tilde{x}_{i j}^{\alpha}=\left[x_{i l}^{\alpha}, x j_{1 u}^{\alpha}\right], \tilde{\lambda}^{\alpha}=\left[\lambda_{l}^{\alpha}, \lambda_{u}^{\alpha}\right]
\end{gathered}
$$

for $0<\alpha \leq 1$ and all $i, j$, where $i=1,2, \ldots, n, j=1,2 \ldots, n$.

The decision makers' confidence over their preferences is included and represented by the $\alpha$-cut. It is developed to minimize the subjectivity of results to experts' judgment and preference. The index of optimism $\mu$ estimates the degree of satisfaction for the judgment matrix $\tilde{A}$. The bigger $\mu$ value shows higher degree of optimism. It can be defined as:

$$
\tilde{a}_{i j}^{\alpha}=\mu \tilde{a}_{i j l}^{\alpha}+(1-\mu) \tilde{a}_{i j l}^{\alpha}, \quad \forall \alpha \in[0,1]
$$

When $\alpha$ is fixed, matrix $\tilde{A}$ can be built. The index of optimism, $\mu$, should first be set to estimate the degree of satisfaction: 


$$
\tilde{A}=\left[\begin{array}{ccccc}
1 & \widetilde{a}_{12}^{\alpha} & \cdots & \cdots & \widetilde{a}_{1 n}^{\alpha} \\
\widetilde{a}_{21}^{\alpha} & 1 & \cdots & \cdots & \widetilde{a}_{2 n}^{\alpha} \\
\vdots & \vdots & \vdots & \vdots & \vdots \\
\widetilde{a}_{n 1}^{\alpha} & \widetilde{a}_{n 2}^{\alpha} & \cdots & \cdots & 1
\end{array}\right]
$$

The consistency ratio (CR) is calculated for all pair-wise judgments between factors. The measure of inconsistency can be defined as the deviation from consistency and is called the consistency index (CI). It can be calculated using the following equation:

$$
\mathrm{CI}=\frac{\left(\lambda_{\max }-1\right)}{\mathrm{n}-1}
$$

Where $n$ is the matrix size.

To directly estimate the consistency of pair-wise judgments the consistency ration (CR) can be used. It can be obtained by dividing CI by a value from the table of random consistency index (RI) (Table 2). The RI values are the average index for randomly generated weights (Saaty, 1980). The equation for obtaining CR is as follow:

$$
C R=\frac{C I}{R I}
$$

Pair-wise comparisons are considered acceptable if CR is less than $10 \%$. Otherwise the comparison is rejected. The last step is calculating the priority weight of each alternative. This can be done by multiplying the matrix of evaluation ratings by the vector of factor weights and summing over all factors.

\begin{tabular}{|c|r|r|r|r|r|r|r|r|r|r|}
\hline Size (n) & 1 & 2 & 3 & 4 & 5 & 6 & 7 & 8 & 9 & 0 \\
\hline RI & 0 & 0 & 0.52 & 0.89 & 1.11 & 1.25 & 1.35 & 1.40 & 1.45 & 1.51 \\
\hline
\end{tabular}

Table 2. The random consistency index (RI) based on Saaty (1980)

\subsection{Fuzzy TOPSIS}

The fuzzy TOPSIS method presented in this study is based on the methodology of Chen and Hwang (1992), with reference to Hwang and Yoon (1981). There are several expressions of Fuzzy TOPSIS in the literature (Kilic, 2012; Ayhan, 2013). The basic idea is that the selected alternative should satisfy two conditions. First, it should have the shortest distance from the ideal solution; and second, it should be the furthest from the counter-ideal solution (Opricovic \& Tzeng, 2003; Nadaban, Dzitac \& Dzitac 2016).

The traditional TOPSIS method uses crisp values for comparisons. As it was discussed in the previous section, crisp numbers fail to represent the expert judgment. Therefore, researchers use linguistic expressions to substitute the crisp values in the traditional TOPSIS method. To develop linguistic expressions and quantify them the fuzzy set theory is used. The fuzzy TOPSIS method is an integration of TOPSIS and fuzzy theory, developed to deal decision making problems with uncertainty (Aydogan, 2012; Baykasoglu, Kaplanoglu, Durmusoglu \& Sahin, 2013, Pourjavad \& Peng, 2017). The steps of Fuzzy TOPSIS method are as follow:

Step 1: Selecting the linguistic variables for the alternatives with respect to criteria

The linguistic variables are associated with a triangular fuzzy number. All $\mathrm{m}$ possible alternatives called $A=\left\{A_{1}\right.$, $\left.A_{2}, \ldots, A_{m}\right\}$ are to be compared against the criteria, $C=\left\{C_{1}, C_{2}, \ldots, C_{n}\right\}$, using the linguistic variables. The weights are noted by $w_{j}(j=1,2, \ldots n)$ and indicate the criteria weights. The decision makers assigning the linguistic variable are noted by $D_{k}(k=1,2, \ldots, K)$. The performance ratings are indicated by $\widetilde{R}_{k}=\tilde{x}_{i j k}(i=1,2, \ldots, m ; j=1,2, \ldots, n$; $k=1,2, \ldots, K)$ that represent the ratings for each expert $D_{k}(k=1,2, \ldots, K)$ for each alternative $A_{i}(i=1,2, \ldots, m)$ with regards to each criterion $C_{j}(j=1,2, \ldots, n)$. The membership function for performance ratings is indicated by $\mu \widetilde{R}_{K}(x)$. Table 3 shows the scale used for ratings. 


\begin{tabular}{|c|c|}
\hline Linguistic variables & Corresponding TFN \\
\hline Very low & $(1,1,2)$ \\
\hline Low & $(2,3,4)$ \\
\hline Medium & $(4,5,6)$ \\
\hline High & $(6,7,8)$ \\
\hline Very high & $(8,9,10)$ \\
\hline
\end{tabular}

Table 3. Linguistic variables for ratings

Step 2: Finding the combined fuzzy ratings for the alternatives

Considering that all expert ratings are triangular fuzzy numbers: $\widetilde{R}_{k}=\left(a_{k}, b_{k}, c_{k}\right), k=1,2, \ldots, K$ then the combined fuzzy rating is:

$\tilde{R}=(a, b, c)$, where

$$
a=\min \left\{a_{k}\right\}, \quad b=\frac{1}{K} \sum_{k=1}^{k} b_{k}, \quad c=\max \left\{c_{k}\right\},
$$

Considering that $\tilde{x}_{i j}=\left(a_{i j k}, b_{j k k}, c_{i j k}\right), I=1,2, \ldots, m ; j=1,2, \ldots, n$ is the rating of $K^{\text {th }}$ decision maker, then the aggregated fuzzy ratings $\tilde{x}_{i j}$ is associated with alternatives with respect to each criteria indicated by:

$\tilde{x}_{i j}=\frac{1}{K}\left(\tilde{x}_{i j}{ }^{1}+\tilde{x}_{i j}{ }^{2}+\ldots+\tilde{x}_{i j}{ }^{k}\right), \tilde{x}_{i j}=\left(a_{i j}, b_{i j}, c_{i j}\right)$, where:

$$
\mathrm{a}_{\mathrm{ij}}=\min \left\{\mathrm{a}_{\mathrm{ijk}}\right\}, \mathrm{b}_{\mathrm{ij}}=\frac{1}{K} \sum_{k=1}^{k} b_{i j k}, \mathrm{c}_{\mathrm{ij}}=\max \left\{\mathrm{c}_{\mathrm{ijk}}\right\},
$$

Step 3: Building the fuzzy decision matrix

The fuzzy decision matrix for the alternatives $(\widetilde{D})$ is built as follows:

$$
\tilde{A}=\left[\begin{array}{ccccc}
\tilde{x}_{11} & \tilde{x}_{12} & \cdots & \cdots & \tilde{x}_{1 n} \\
\tilde{x}_{21} & \tilde{x}_{22} & \cdots & \cdots & \tilde{x}_{2 n} \\
\vdots & \vdots & \vdots & \vdots & \vdots \\
\tilde{x}_{m 1} & \tilde{x}_{m 2} & \cdots & \cdots & \tilde{x}_{m n}
\end{array}\right] \quad i=1,2, \ldots, m ; j=1,2, \ldots, n
$$

Step 4: Building the Normalized fuzzy decision matrix

To convert the raw criteria ratings into a comparable scale a linear scale transformation is used. The normalized fuzzy decision matrix $\widetilde{R}$ is given by:

$$
\tilde{R}=\left[r_{i j}\right]_{m \times n}, \quad i=1,2, \ldots, m ; j=1,2, \ldots, n
$$

Where

$$
\begin{gathered}
\tilde{r}_{i j}=\left(\frac{a_{i j}}{c_{j}^{+}}, \frac{b_{i j}}{c_{j}^{+}}, \frac{c_{i j}}{c_{j}^{+}}\right) \text {and } c_{j}^{+}=\max c_{i j} \\
\tilde{r}_{i j}=\left(\frac{a_{j}^{-}}{c_{i j}}, \frac{a_{j}^{-}}{b_{i j}}, \frac{a_{j}^{-}}{a_{i j}}\right) \text { and } a_{j}^{-}=\min a_{i j}
\end{gathered}
$$

Step 5: building the weighted normalized matrix

By multiplying the weights $\left(W_{j}\right)$ of evaluation criteria with the normalized fuzzy decision matrix $\tilde{r}_{i j}$ the weighted normalized matrix $\tilde{v}$ for criteria is calculated. 


$$
\tilde{V}=\left[\tilde{v}_{i j}\right]_{m \times n}, i=1,2, \ldots, m ; j=1,2, \ldots, n \quad \text { where } \quad \tilde{v}_{i j}=\tilde{r}_{i j} \mathrm{~W}_{j}
$$

Step 6: determining the fuzzy ideal solution (FPIS) and fuzzy negative ideal solution (FNIS)

The FPIS and FNIS of the alternatives are calculated as follows:

$$
\begin{aligned}
& A^{+}=\left(\tilde{v}_{1}^{+}, \tilde{v}_{2}^{+}, \ldots . . \tilde{v}_{n}^{+}\right) \text {where } \tilde{v}_{j}^{+}=\left(\tilde{c}_{j}^{+}, \tilde{c}_{j}^{+}, \tilde{c}_{j}^{+}\right) \text {and } \tilde{c}_{j}^{+}=\max \left\{\tilde{c}_{i j}\right\} \\
& A^{-}=\left(\tilde{v}_{1}^{-}, \tilde{v}_{2}^{-}, \ldots \ldots \tilde{v}_{n}^{-}\right) \text {where } \tilde{v}_{j}^{-}=\left(a_{j}^{-}, \tilde{a}_{j}^{-}, \tilde{a}_{j}^{-}\right) \text {and } \tilde{a}_{j}^{-}=\min \left\{\tilde{a}_{i j}\right\} \\
& \forall i=1,2, \ldots, m \text { and } j=1,2, \ldots, n
\end{aligned}
$$

Step 7: Finding each alternative's distance from FPIS and FNIS

To find the distance $\left(d_{i}^{+}, d_{i}^{-}\right)$of each weighted alternative $i=1,2, \ldots, m$ from the FPIS and the FNIS the following formulas can be used:

$$
\begin{gathered}
d_{i}^{+}=\sum_{j=1}^{n} d v\left(\tilde{v}_{i j}, \tilde{v}_{j}^{+}\right) \mathrm{i}=1,2, \ldots . . \mathrm{m} \\
d_{i}^{-}=\sum_{j=1}^{n} d v\left(\tilde{v}_{i j}, \tilde{v}_{j}^{-}\right) \quad i=1,2, \ldots, m
\end{gathered}
$$

Step 8: Finding the closeness coefficient $\left(C C_{i}\right)$ of each alternative

The closeness coefficient $C C_{i}$ is the simultaneous distances to the fuzzy positive ideal solution $\left(A^{+}\right)$and the fuzzy negative ideal solution $\left(A^{-}\right)$. It can be estimated using the following formula:

$$
C C_{i}=\frac{d_{i}^{-}}{d_{i}^{-}+d_{i}^{+}}
$$

Step 9: ranking the alternatives

The alternatives are evaluated and ranked according to the closeness coefficient $\left(C C_{i}\right)$ from the highest to the lowest scored alternative.

\subsection{Implementation of the Proposed Model to Evaluate PPCPs}

MCDM models are effective methods to solve the problems with different criteria. Evaluating the alternatives based on the measurement criteria is the purpose of this study. Dissimilar scale and nature of measurement criteria highlights the effectiveness of MCDM methods for this purpose. Due to the involvement of human experts, the conventional MCDM methods are not suitable to deal with imprecise data. Therefore, the fuzzy set theory proposed by Zadeh is applied to improve the decision making processes. This study integrates AHP and TOPSIS methods with fuzzy theory to evaluate the proposed alternatives. Criteria weights are obtained following the fuzzy AHP method and fuzzy TOPSIS is used to evaluate the alternatives with respect to criteria. Figure 2 shows the proposed framework of this study. The detailed description of the procedures is described as follow:

The expert panel consisting of kaizen groups, industry practitioners, and researchers is formed to conduct the pairwise judgments, identifying the criteria, and recognizing the alternatives.

Hybrid pull production policies are developed and optimized by selecting the number of kabanas. Similar to the approach followed by Khojasteh-Ghamari (2009) a tree shaped production and assembly system is developed and the circulation of cards is designed. 7 ConWIP-Kanban alternatives are illustrated (Figure 3 to 9) using activity interaction diagram (Sato \& Praehofer, 1997). In this diagram production processes, queues, and connection arrows are demonstrated. The diagram shows the circulation of cards and the flow of material. The developed hybrid alternatives are referred to as $A_{\mathrm{i}}$, where $l=1,2, \ldots, 4$. The WIP kabanas are circulated in between buffers $\mathrm{b}_{\mathrm{i}}$ and 
processes $\mathrm{p}_{\mathrm{i}}$ and operation Kanbans circulate between processes. All the developed systems consist of both Kanban types similar to the common Kanban system (Thürer et al., 2016), or they are a combination of Kanban and ConWIP systems. Therefore, they are all called hybrid PPCPs.

The mechanism of $A_{1}$ is explained as an example. The first set of Kanbans are WIP Kanbans, since they circulate in between the designated buffer and a process. In this situation once, a new demand consumes a part, the attached WIP kanabn card is released. The WIP Kanban travels to the preceding process and authorizes the production. Upon availability of a part preceding buffer to feed the process and the process itself, the process starts. The process can be unavailable due to the breakdown. The cards circulate in between all the processes. The raw material is available to feed the initiating processes.

Based on the literature survey, the important parameters to measure the performance of pull production policies are selected. The parameters are defined and methods to measure them are explained. The performance measures are designed to be work-in-process level (WIP), lead time (LT), lost demand (LD), and delay (D). These measures are considered to be the criteria for the problem and denoted by cj where $C_{j}=1,2, \ldots, 4$ represents the WIP, LT, LD and $D$ consecutively. $C_{j}$ value is considered to be a triangular fuzzy number $C_{j}=\left(l_{j}, m_{j}, u_{j}\right)$, where $l_{j}$ is the lowest measured performance result, $m_{j}$ is the average, and $u_{j p}$ is the highest measured performance result in a non-deterministic approach. For example considering the second hybrid $\operatorname{PPCP}\left(A_{4}\right)$ the level of WIP as the first performance measure is represented as: $C_{1}^{4}=\left(l_{1}^{4}, m_{1}^{4}, u_{1}^{4}\right)$, where $l_{1}^{4}$ is the lowest WIP level for $A_{4}, m_{1}^{4}$ is the average WIP level for $A_{4}$, and $u_{1}^{4}$ is the highest WIP level for $A_{4}$.

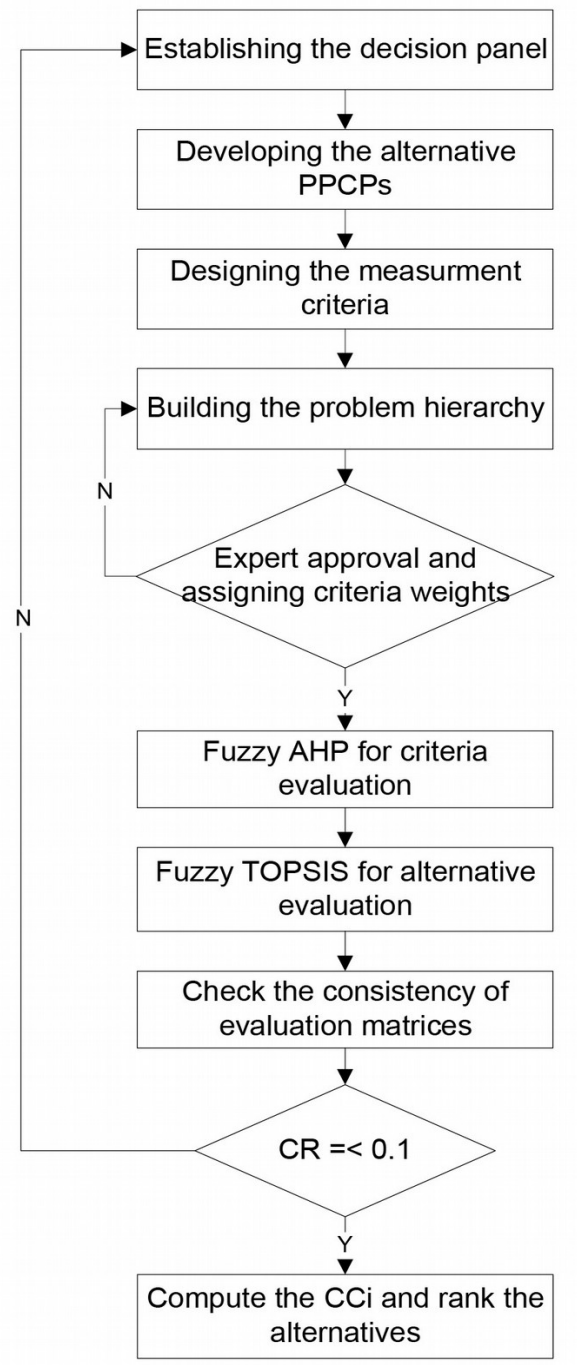

Figure 2. Proposed fuzzy multi-criteria decision-making framework 
Linguistic variables and related fuzzy values are selected. The linguistic variables are used to compare the parameters and alternatives. Their representative fuzzy sets are triangular expressions. Due to the qualitative nature of the performance parameters, developing a quantitative expression to consider the impact of each parameter is subjective. Ranking the parameters, the priorities and preferences of decision maker is considered using the linguistic variables.

To compare the performance of PPCPs the decision maker qualitative expression is translated into fuzzy numbers. For this purpose, linguistic variables similar to the previous step are used. In this step, the pair-wise comparisons are in between the PPCPs, as alternatives, with regards to each performance measurement criteria. Triangular fuzzy values are selected to represent the linguistic variables. The variables to compare the parameters are set to be: very low, low, medium, high, very high. To express the performance of each PPCP the variables are: Very poor, poor, medium, good, very good. In the second method, the comparison is made based on the obtained triangular fuzzy numbers from step 2.

After forming a decision hierarchy, the 4 criteria weights are found using fuzzy AHP. Expert evaluation matrix is based on the scales presented in Table 1. The final evaluation matrix is formed by finding the arithmetic mean of the values from the evaluations. To decide the relative importance of each pair of JIT performance measures and PPCP alternatives the evaluation matrix A $(n$ by $m)$ is formed. The objects $\left(a_{i j}=(u, m, l)\right)$ of this matrix $(A)$ are triangular fuzzy numbers if $u-l>0$. Otherwise the pair-wise comparison is a nonfuzzy number. An example of a non-fuzzy judgment is the pair-wise comparison of objects $i$ and $j$ when $i=j$.

Figure 2 shows the procedure for the fuzzy multi-criteria decision-making system.

\subsection{Experimental Results}

The production line considered in this case is from a manufacturer of elecro-mechanical car keys and consists of two branches, which are plastic injection and machining line, which feed one assembly line. The Production line with two production stages and two buffer stations is the metal press line. At the beginning of the press line an unlimited buffer of raw material which is metal sheets is provided. The single stage production line is the plastic injection and the raw material buffer is provided at the beginning of the process. The plastic and metal parts feed the assembly line with two working stations and two buffers.

Collecting the data from manufacturing and assembly departments is based on a time study. Observations to determine the process time for each station were in different working days and included the day and afternoon shifts. Minimum number of 120 robust observations for each process step was performed. Chronometers were used to measure the process times and the standard working time is calculated. To achieve normal working condition, workers did not notice the time measuring process. Work instruction documents were reviewed to assure that the processes are following their standards. The data was controlled and selected using Data Control Chart. If the data is beyond the acceptance limit it is eliminated based on expert justifications. Demands are determined by reviewing the past trends. Manufacturer may have different orders for each month. Exponential distribution with time factor of 0.5 is considered for demand variable.

For the purpose of running an experimental discrete event computer simulation, statistical analysis is performed on the observed input data. Using the distribution fitting, normal distributions are suggested for the processing time of the stations. Verification of the data is based on statistical methods following the Estimated Error method and Estimated Covariance method. Following the statistical analysis, the processing time of station P is from a normal distribution with parameters $\mu$ and $\sigma . \mu$ represents the average processing time and $\sigma$ represents the standard deviation. The estimated parameters are as follows: $P_{11}(\mu=0.72, \sigma=0.52), P_{12}(\mu=0.77, \sigma=0.55), P_{21}(\mu=0.78$, $\sigma=0.56), P_{1}(\mu=0.51, \sigma=0.37)$, and $P_{2}(\mu=1.17, \sigma=0.40)$. To examine whether the normal distribution is the true representative of the observed processing times the $Z$-test was performed. $h$ value returns null for every station that shows the standard processing time comes from a normal distribution with mean $\mu$ and standard deviation $\sigma$ at $5 \%$ significance level. The alternative hypothesis that the mean is not $\mu$ is rejected. The standard time for each workstation and job orders which is based on demands are considered as the independent variables. 
Common assumptions for developing the simulation model are applied. It is assumed that material is transported in units of one (one-batch flow). Transfer time for materials is ignored. The Kanbans are assumed to flow instantly upon availability. Jobs are considered to be following a first come first serve (FIFO) policy to be completed in each station. And, there is no shortage of raw material from supplier to feed the first stations of each stage.

Number of cards, capacities and buffers are set through soft experiments for the best possible performance. Extra operation Kanban cards or buffer capacities were added to improve the performance. Through a large number of replications, the better parameters were changed and the results were found. Every replication ran for 1000 order entities. Over 140 replications were conducted and 100 results that represented the best performance of the alternatives were selected.

The following steps are based on the proposed approach and are explained for the studied case.

Step 1: Defining the performance measurement criteria and alternatives

The measurement criteria and alternatives are identified at the first step to construct the hierarchical decision structure. The measurement criteria are identified by reviewing the literature and recognized by the decision panel. The decision panel consisted of a kaizen group of ten workers and managers from different organizational levels and four experts from academia. The panel recognized the designed alternatives for controlling the production system. The PPCPS are considered the alternatives. Figure 3 to 9 show the alternative PPCPs for the described manufacturing and assembly system in which two lines, metal press and plastic injection, feed the assembly line.

Four measurement criteria to evaluate the performance of PPCPs are recognized for this case. Two of the criteria are time based while the other two are not. They are described as follow:

- Level of work-in-process (WIP)

Excessive inventory is reported as source of waste in lean manufacturing. WIP is the inventory that circulates in production line and JIT method aims to reduce the level of WIP. Researchers used WIP level repeatedly to measure the performance of the production system WIP level reported as the average number of batches circulating in the line.

- $\quad$ Lead time (LT)

The reduction of lead time is recognized as an important objective to improve the production system. It is defined as the time from when an order is initiated in the system until it is completed through the production process. As a time based factor, LT is recognized as the second criteria to evaluate the PPCPs.

- $\quad$ Lost demand (LD)

Satisfying the demand exactly when the order arrives is the goal of JIT production. If there is no complete product available at the time of order arrival the system records one lost in satisfying the demand immediately. However, the order remains in the system to be satisfied as a delayed order. LD is recognized as the third measurement criteria.

- Delay (D)

If the demand is not satisfied when a new order arrives due to the shortage of finished product delay happens. This measurement criterion has a negative impact on the performance of the system. Therefore, the higher delay results in the lower preference of PPCP. Delay is a time based measure. 


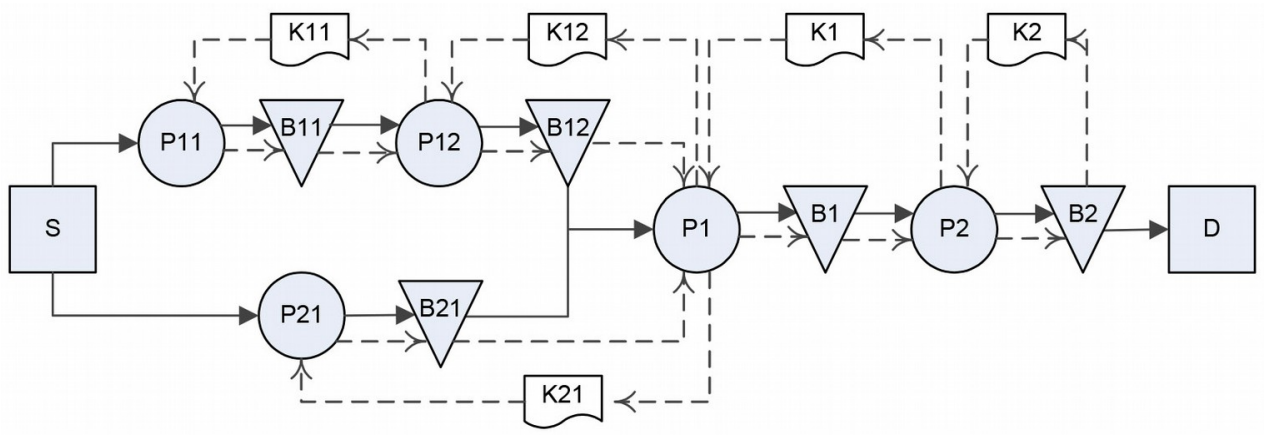

Figure 3. Conceptual mechanism of Kanban (A1) system

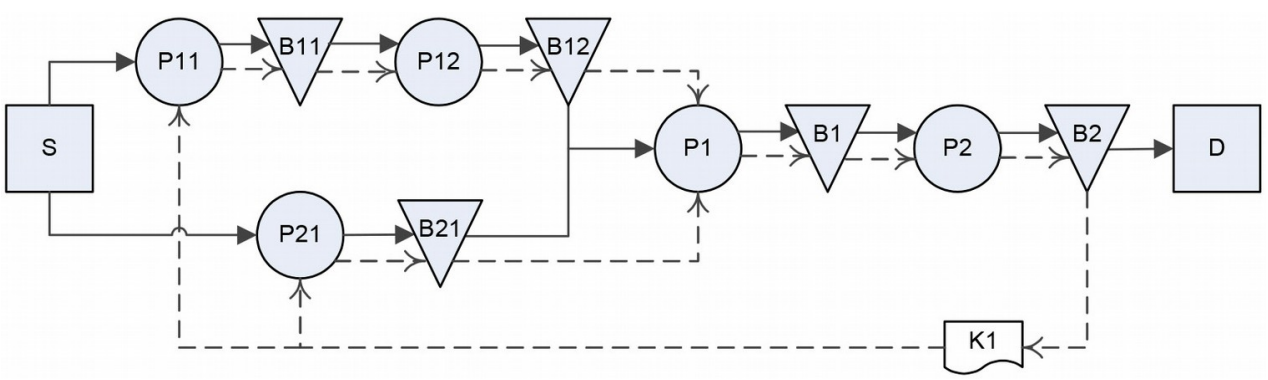

Figure 4. Conceptual mechanism of ConWIP (A2) system

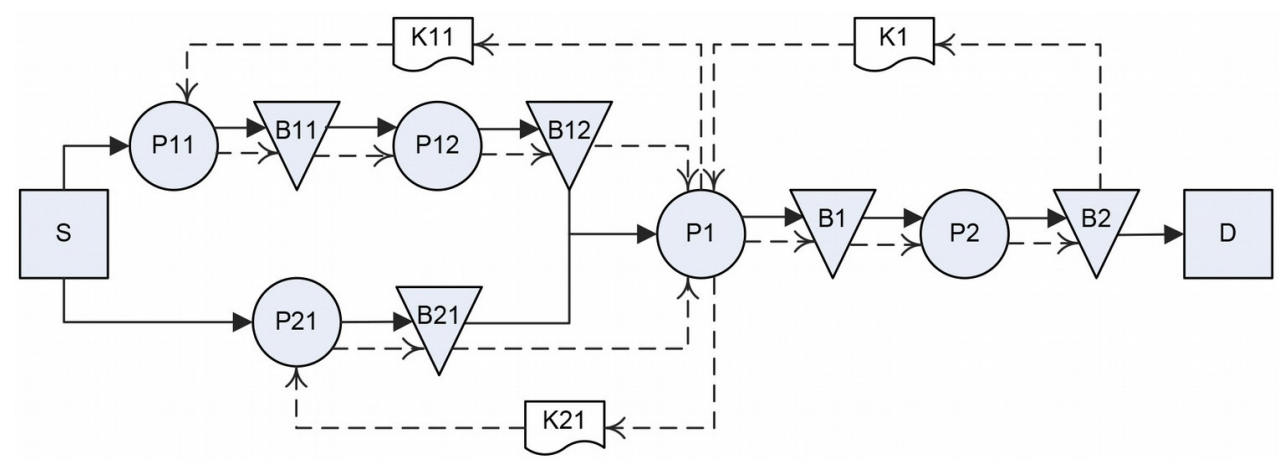

Figure 5. Conceptual mechanism of hybrid1 (A3) system

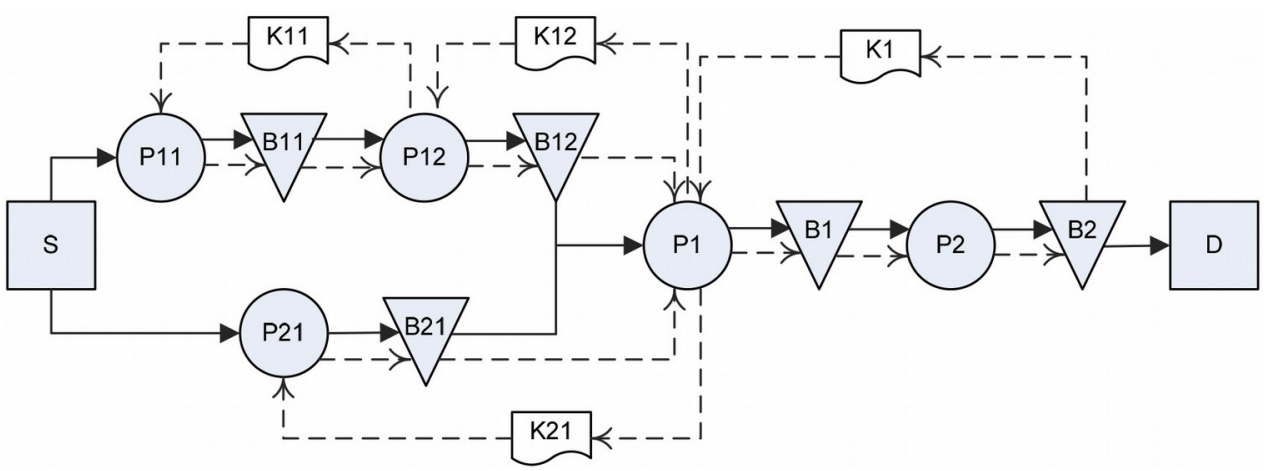

Figure 6. Conceptual mechanism of Hybrid2 (A4) system 


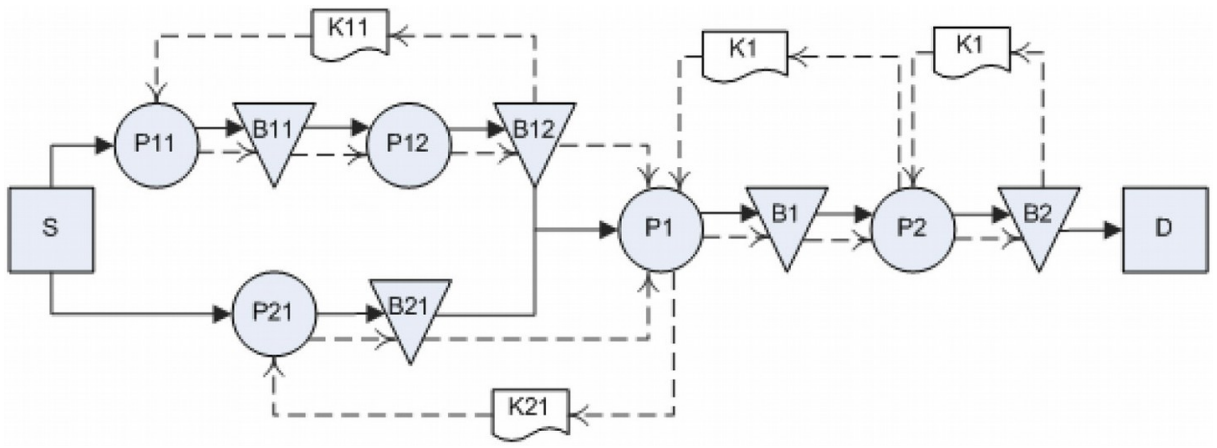

Figure 7. Conceptual mechanism of Hybrid3 (A5) system

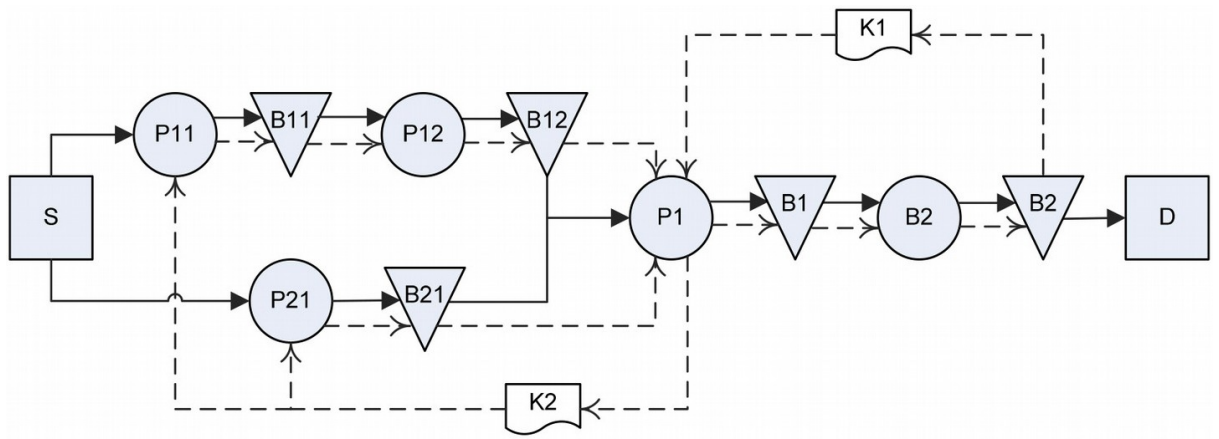

Figure 8. Conceptual mechanism of Hybrid4 (A6) system

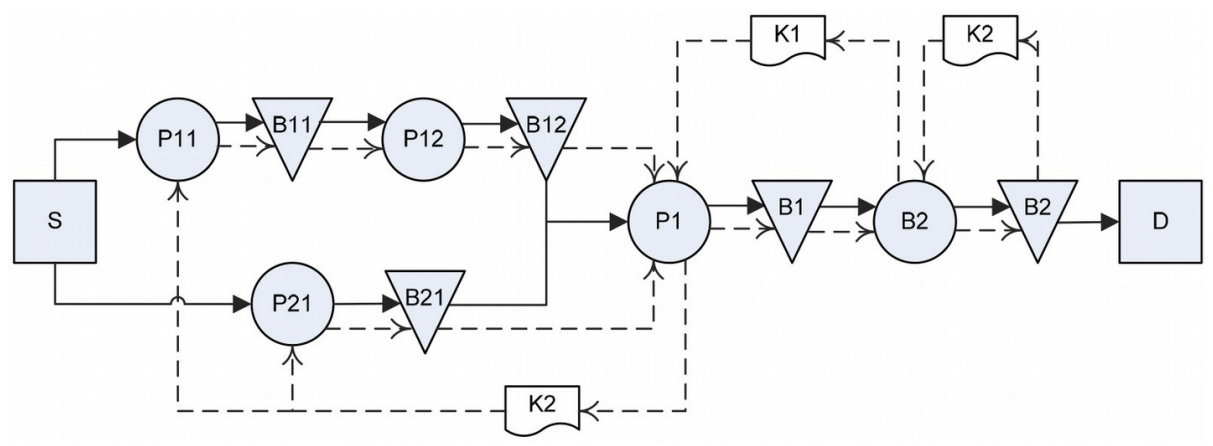

Figure 9. Conceptual mechanism of Hybrid5 (A7) system

Considering the objective, criteria and the developed alternatives the decision-making structure can be built hierarchically. There are there levels in the decisions hierarchy as displayed in Figure 10. The first level is the main goal which is selection of tee best PPCP, the measurement criteria are in the second level, and alternatives are in the third level of the hierarchy.

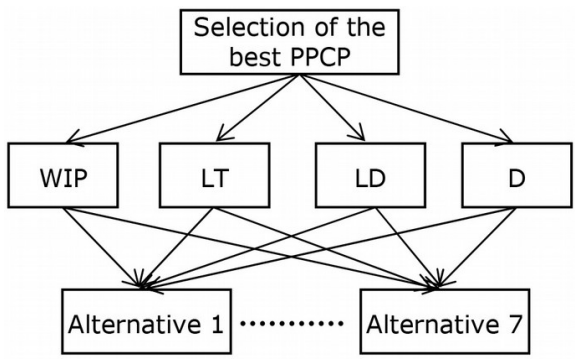

Figure 10. Decision making hierarchical construction 
Step 2: finding the weights of criteria with Fuzzy AHP

In the second step, the pair-wise comparison of measurement criteria is made based on experts' decision. Table 4 shows the criteria pair-wise comparison of one expert $\left(D_{1}\right)$ with fuzzy numbers based on fuzzy AHP method.

\begin{tabular}{|c|c|c|c|c|}
\hline & WIP & LT & LD & D \\
\hline WIP & 1 & $\tilde{3}$ & $\tilde{5}$ & $\tilde{7}$ \\
\hline LT & $\tilde{3}^{-1}$ & 1 & $\tilde{1}$ & $\tilde{5}$ \\
\hline LD & $\tilde{5}^{-1}$ & $\tilde{1}^{-1}$ & 1 & $\tilde{3}$ \\
\hline D & $\tilde{7}^{-1}$ & $\tilde{5}^{-1}$ & $\tilde{3}^{-1}$ & 1 \\
\hline
\end{tabular}

Table 4. Fuzzy comparison matrix of the criteria using triangular fuzzy numbers

The calculations to find the CR value are presented for $D_{1}$ based on the method in Section 3.2.

By applying Equation (6) the lower and upper limits of TFNs with respect to is defined as follows:

$$
\begin{array}{ll}
\tilde{1}_{\alpha}=[1,3-2 \alpha], & \tilde{1}_{\alpha}^{-1}=\left[\frac{1}{3-2 \alpha}, 1\right], \\
\tilde{3}_{\alpha}=[1+2 \alpha, 5-2 \alpha], & \tilde{3}_{\alpha}^{-1}=\left[\frac{1}{5-2 \alpha}, \frac{1}{1+2 \alpha}\right], \\
\tilde{5}_{\alpha}=[3+2 \alpha, 7-2 \alpha], & \tilde{5}_{\alpha}^{-1}=\left[\frac{1}{7-2 \alpha}, \frac{1}{3+2 \alpha}\right], \\
\tilde{7}_{\alpha}=[5+2 \alpha, 9-2 \alpha], & \tilde{7}_{\alpha}^{-1}=\left[\frac{1}{9-2 \alpha}, \frac{1}{5+2 \alpha}\right], \\
\tilde{\rho}_{\alpha}=[7+2 \alpha, 11-2 \alpha], & \tilde{\rho}_{\alpha}^{-1}=\left[\frac{1}{11-2 \alpha}, \frac{1}{7+2 \alpha}\right.
\end{array}
$$

Using Equation (7) and substituting $\alpha=0.5$ and $\mu=0.5$ into the expressions the $\alpha$-cuts comparison matrices are obtained. Table 5 illustrates the $\alpha$-Cuts fuzzy comparison matrix for $D_{1}$ as an example.

\begin{tabular}{|c|c|c|c|c|}
\hline & WIP & LT & LD & D \\
\hline WIP & 1 & {$[2,4]$} & {$[4,6]$} & {$[6,8]$} \\
\hline LT & {$[1 / 4,1 / 2]$} & 1 & 1 & {$[4,6]$} \\
\hline LD & {$[1 / 6,1 / 4]$} & 1 & 1 & {$[2,4]$} \\
\hline D & {$[1 / 8,1 / 6]$} & {$[1 / 6,1 / 4]$} & {$[1 / 4,1 / 2]$} & 1 \\
\hline
\end{tabular}

Table 5. $\alpha$-Cuts fuzzy comparison matrix for the criteria $(\alpha=0.5, \mu=0.5)$

Let Table 6 be the representative of the $\alpha$-Cuts fuzzy comparison matrix for expert $D_{1}$. Then $\lambda$ values are calculated using Equation (5) and by solving $\operatorname{det}(A 1-\lambda I)=0$ and found to be: $\left(\lambda_{1}, \lambda_{2}, \lambda_{3}, \lambda_{4}\right)=(4.20430,4.18635,4.17064$, 4.19796). Therefore, $\tilde{\lambda}_{\max }=4.20430$. 


\begin{tabular}{|c|r|r|r|r|}
\hline & \multicolumn{1}{|c|}{ WIP } & LT & LD & D \\
\hline WIP & 1 & 3 & 5 & 7 \\
\hline LT & 0.375 & 1 & 1 & 5 \\
\hline LD & 0.21 & 1 & 1 & 3 \\
\hline D & 0.146 & 0.21 & 0.375 & 1 \\
\hline
\end{tabular}

Table 6. Eigenvector for comparison matrix of the criteria

From Table 2 the RI, when $n=4$, is 0.89. Using Equations (9) and (10) the consistency index and the consistency ratio of the matrix is calculated as follows:

$$
\begin{gathered}
C I=\frac{\lambda_{\max }-1}{n-1}=\frac{4.20430-1}{4-1}=0.06810 \\
C R=\frac{C I}{C R}=\frac{0.06810}{0.89}=0.076519
\end{gathered}
$$

The consistency ratio is less than $10 \%$ that shows the consistency of $D_{1}$ judgment. Similar calculations are performed for all the expert judgments $\left(D_{\mathrm{k}}, k=2,3,4,5\right)$ and CR was observed to be less than $10 \%$. By cumulating and normalizing the obtained criteria weights from all the experts the e-vector for weights of WIP, LT, LD, and D is equal to: $(0.55,0.29,0.13,0.04)$.

Step 3: Evaluating the alternatives with fuzzy TOPSIS and determining the final ranks

The alternative PPCPs were compared based on different criteria using linguistic variables presented in Table 3. The comparison results for one expert are presented in Table 7 due to the extensive length of full comparisons.

The linguistic expressions are translated to corresponding TFNs and built in the fuzzy evaluation matrix presented in Table 8. Using Equation 12 the aggregated fuzzy weights for alternatives is calculated and displayed in Table 9.

Since all the identified criteria are desired to be minimized, the objective of this study is to select the alternative with the minimum measured criteria. Using Equation 16 the normalized results are calculated and presented in Table 10. The weighted evaluation matrix is shown by Table 11 using the Equation 17 to calculate the criteria weights.

\begin{tabular}{|c|c|c|c|c|}
\hline & WIP & LT & LD & D \\
\hline A1 & L & M & H & M \\
\hline A2 & VH & M & H & M \\
\hline A3 & H & VH & VH & VH \\
\hline A4 & M & H & VH & VH \\
\hline A5 & M & H & VH & H \\
\hline A6 & M & L & L & L \\
\hline A7 & VH & L & L & L \\
\hline
\end{tabular}

Table 7. Linguistic scale evaluation matrix for the solutions 


\begin{tabular}{|c|c|c|c|c|}
\hline & WIP & LT & LD & D \\
\hline A1 & $(2,3,4)$ & $(4,5,6)$ & $(6,7,8)$ & $(4,5,6)$ \\
\hline A2 & $(8,9,10)$ & $(4,5,6)$ & $(6,7,8)$ & $(4,5,6)$ \\
\hline A3 & $(6,7,8)$ & $(8,9,10)$ & $(8,9,10)$ & $(8,9,10)$ \\
\hline A4 & $(4,5,6)$ & $(6,7,8)$ & $(8,9,10)$ & $(8,9,10)$ \\
\hline A5 & $(4,5,6)$ & $(6,7,8)$ & $(8,9,10)$ & $(6,7,8)$ \\
\hline A6 & $(4,5,6)$ & $(2,3,4)$ & $(2,3,4)$ & $(2,3,4)$ \\
\hline A7 & $(8,9,10)$ & $(2,3,4)$ & $(2,3,4)$ & $(2,3,4)$ \\
\hline
\end{tabular}

Table 8. Fuzzy evaluations matrix for solutions

\begin{tabular}{|c|c|c|c|c|}
\hline & WIP & LT & LD & D \\
\hline A1 & $(2,5.8,8)$ & $(4,8,10)$ & $(1,5.4,8)$ & $(2,4.6,6)$ \\
\hline A2 & $(4,7.2,10)$ & $(4,6.2,10)$ & $(1,3.8,6)$ & $(1,3.8,6)$ \\
\hline A3 & $(6,8.8,10)$ & $(6,7.8,10)$ & $(2,6.4,8)$ & $(2,4.6,8)$ \\
\hline A4 & $(4,6.8,10)$ & $(2,6.2,8)$ & $(6,7.6,10)$ & $(4,5.4,8)$ \\
\hline A5 & $(4,8.6,10)$ & $(2,4.4,8)$ & $(1,3.8,6)$ & $(1,2.8,6)$ \\
\hline A6 & $(1,6.4,8)$ & $(1,5.8,8)$ & $(1,5.8,8)$ & $(4,7.2,10)$ \\
\hline A7 & $(2,6.1,8)$ & $(1,2.4,6)$ & $(2,4.8,8)$ & $(1,3,6)$ \\
\hline
\end{tabular}

Table 9. Aggregate fuzzy decision matrix for solutions

\begin{tabular}{|c|c|c|c|c|}
\hline & WIP & LT & LD & D \\
\hline A1 & $(0.125,0.172,0.5)$ & $(0.1,0.125,0.25)$ & $(0.125,0.185,1)$ & $(0.166,0.217,0.5)$ \\
\hline A2 & $(0.1,0.138,0.25)$ & $(0.1,0.161,0.25)$ & $(0.166,0.263,1)$ & $(0.166,0.263,1)$ \\
\hline A3 & $(0.1,0.114,0.166)$ & $(0.1,0.128,0.166)$ & $(0.125,0.156,0.5)$ & $(0.125,0.217,0.5)$ \\
\hline A4 & $(0.1,0.147,0.25)$ & $(0.125,0.161,0.5)$ & $(0.1,0.131,0.166)$ & $(0.125,0.185,0.25)$ \\
\hline A5 & $(0.1,0.116,0.25)$ & $(0.125,0.227,0.5)$ & $(0.166,0.263,1)$ & $(0.166,0.357,1)$ \\
\hline A6 & $(0.125,0.156,1)$ & $(0.166,0.172,1)$ & $(0.166,0.172,1)$ & $(0.1,0.138,0.25)$ \\
\hline A7 & $(0.125,0.164,0.5)$ & $(0.166,0.416,1)$ & $(0.125,0.208,0.5)$ & $(0.166,0.263,1)$ \\
\hline
\end{tabular}

Table 10. Normalized fuzzy decision matrix for solutions

\begin{tabular}{|c|c|c|c|c|}
\hline & WIP & LT & LD & D \\
\hline A1 & $(0.006,0.009,0.027)$ & $(0.029,0.036,0.072)$ & $(0.016,0.024,0.130)$ & $(0.006,0.008,0.020)$ \\
\hline A2 & $(0.006,0.007,0.013)$ & $(0.029,0.046,0.072)$ & $(0.021,0.034,0.130)$ & $(0.006,0.010,0.040)$ \\
\hline A3 & $(0.005,0.006,0.009)$ & $(0.029,0.037,0.048)$ & $(0.016,0.020,0.065)$ & $(0.005,0.008,0.020)$ \\
\hline A4 & $(0.005,0.008,0.013)$ & $(0.036,0.046,0.145)$ & $(0.013,0.017,0.021)$ & $(0.005,0.007,0.010)$ \\
\hline A5 & $(0.005,0.006,0.013)$ & $(0.036,0.065,0.145)$ & $(0.021,0.034,0.130)$ & $(0.006,0.014,0.040)$ \\
\hline A6 & $(0.006,0.008,0.055)$ & $(0.048,0.049,0.290)$ & $(0.021,0.022,0.130)$ & $(0.004,0.005,0.010)$ \\
\hline A7 & $(0.006,0.009,0.027)$ & $(0.048,0.120,0.290)$ & $(0.016,0.27,0.065)$ & $(0.006,0.010,0.040)$ \\
\hline
\end{tabular}

Table 11. Weighted normalized fuzzy decision matrix for solutions 
All the criteria are aimed to be minimized in this study. Therefore, fuzzy positive-ideal solution (FPIS, $A^{+}$) and fuzzy negative-ideal solution (FNIS, $\left.A^{-}\right)$for all the criteria are considered with $\tilde{v}^{+}=(0,0,0)$ and $\tilde{v}^{-}=(1,1,1)$. Then, using the Equations (20) and (21), the distance $d v$ of each alternative from FPIS $\left(A^{+}\right)$and FNIS $\left(A^{-}\right)$is calculated. For example, $C C_{i}$ calculation for ConWIP system (alternative 2 ) is as follows:

$$
\begin{aligned}
& d_{1}^{+}= \sqrt{\frac{1}{3}\left[(0-0.006875)^{2}+(0-0.00946)^{2}+(0-0.0275)^{2}\right]}+ \\
& \sqrt{\frac{1}{3}\left[(0-0.0290)^{2}+(0-0.03625)^{2}+(0-0.0725)^{2}\right]}+ \\
& \sqrt{\frac{1}{3}\left[(0-0.01625)^{2}+(0-0.02405)^{2}+(0-0.1300)^{2}\right]}+ \\
& d_{1}^{-}= \sqrt{\frac{1}{3}\left[(0-0.00664)^{2}+(0-0.00868)^{2}+(0-0.0200)^{2}\right]}=0.157019 \\
& \sqrt{\frac{1}{3}\left[(0-0.0290)^{2}+(0-0.03625)^{2}+(0-0.0725)^{2}\right]}+ \\
& \sqrt{\frac{1}{3}\left[(0-0.01625)^{2}+(0-0.02405)^{2}+(0-0.1300)^{2}\right]}+ \\
& \sqrt{\frac{1}{3}\left[(0-0.00664)^{2}+(0-0.00868)^{2}+(0-0.0200)^{2}\right]}=3.872607 \\
& \\
& C_{i}=\frac{d_{1}^{-}}{d_{1}^{-}+d_{1}^{+}}=0.96103
\end{aligned}
$$

$d_{i}^{-}, d_{i}^{+}$and $C C_{i}$ are similarly calculated for the other PPCP alternatives. Table 12 shows the final results summary.

\begin{tabular}{|c|r|r|r|r|}
\hline Alternative & \multicolumn{1}{c|}{$\boldsymbol{d}_{i}^{+}$} & \multicolumn{1}{c|}{$\boldsymbol{d}_{i}^{-}$} & \multicolumn{1}{c|}{$\boldsymbol{C C}_{\boldsymbol{i}}$} & \multicolumn{2}{|c|}{ Rank } \\
\hline A1 & 0.16492 & 3.86222 & 0.959048 & 4 \\
\hline A2 & 0.15702 & 3.87261 & 0.961034 & 3 \\
\hline A3 & 0.09936 & 3.91018 & 0.97522 & 1 \\
\hline A4 & 0.12544 & 3.89155 & 0.968772 & 2 \\
\hline A5 & 0.20702 & 3.82937 & 0.948711 & 5 \\
\hline A6 & 0.28869 & 3.79170 & 0.92925 & 7 \\
\hline A7 & 0.26653 & 3.78388 & 0.934196 & 6 \\
\hline
\end{tabular}

Table 12. Fuzzy TOPSIS results

Based on $C C_{i}$ values, the final alternative ranking is found to be: Hybrid 1 (A3) $>$ Hybrid 2 (A4) $>$ Kanban (A1) $>$ ConWIP (A2) > Hybrid 3 (A5) > Hybrid 5 (A7) > Hybrid 4 (A6). The PPCPs with the higher $C C_{i}$ value and lower ranks are more suitable to be implemented.

\section{Discussion}

\subsection{Interpretation of Results}

The first proposed system that obtained the highest rank among alternatives was identified to have an excellent performance in terms of lead time, lost demand and delay. The WIP measure is also very good for the first 
proposed hybrid system. The control system was ranked third in WIP level and was ranked first in the other three measurement criteria. Despite the higher importance of WIP level in comparison to other criteria the alternative has obtained the highest rank in the overall evaluation. Having an insight investigation on the mechanism of the third alternatives, the system appears like three connected ConWIP systems. If every level of production and assembly is considered separately, the proposed alternative suggests three connected ConWIP system. In this configuration, each of the ConWIP systems is assigned to one level of production.

The second proposed hybrid system that is ranked second most desirable policy similarly shares two of the ConWIP loops in the first hybrid which are K1 and K21. However instead of having a single K12 loop, it has two loops in the manufacturing line that resembles a Kanban policy. Although the hybrid 2 policy was ranked 5 in terms of WIP, it is ranked second in all other criteria. The high level of WIP in this policy can be interpreted as a result of higher number of loops and associated Kanban cards which allow for a higher number of parts proceeding in the system.

Comparing the Kanban and ConWIP policies the results show that ConWIP policy has a higher desirability for the studied production system. A detailed study of measurement criteria reveals that Kanban resulted in a much higher WIP level compared to ConWIP. However, similar to the second hybrid policy, this can be explained as result of higher number of loops and associated Kanban cards. Both Kanban and ConWIP performed very closely in terms of LT, LD, and D criteria.

The fifth and fourth hybrid production control policies are listed at the bottom of the ranking list. Both these systems share a common Kanban card stack at the multi-production levels. Hybrid 4 performs better in terms of WIP level. The assembly line in this system is controlled by a single loop of Kanbans while hybrid 5 has an extra loop at the assembly level.

\subsection{Managerial Implications}

Development of hybrid pull production control policies: researchers developed and proposed various policies to control the production system. The detailed mechanism of the policies, however, is unclear in many studies that compare the systems. The specific conditions of production environment also affect the results obtained for different mechanisms. Hybrid production policies can be developed by integrating various policies based on the specifications of the production environment. The hybrid policies are considered alternatives for management to decide on which policy to implement. The criteria to select the alternative can be obtained based on organizational priorities.

Designing the Kanban loops for pull production policies: The results from this study show that exclusive Kanban loops for different stages of production can control the level of inventory in the local production stages. However, due to higher number of Kanbans devoted to control loops, the level of WIP will be higher. Therefore, in respect to WIP level, production control systems will have a closer performance if they utilize same number of Kanban cards.

Sharing the Kanban card stacks among different production levels: As it is shown in the example studied in this research, when parallel production levels with different number of stages share the Kanban cards the performance is low. However, sharing the stack for the purpose of reducing the number of Kanban cards can be a biennial strategy if the parallel lines are balanced.

Using fuzzy multi-criteria decision-making techniques for selecting the best policy: This study applied fuzzy AHP technique to compare the criteria. Considering different criteria and assigning weights to them represents the priorities that management aims to address. Fuzzy TOPSIS technique is used to rank the alternatives with respect to criteria. Kaizen groups and experts can interpret the results for different alternatives. Linguistic expression of decision makers can be translated to quantitative values using fuzzy techniques as described by this study.

\section{Conclusions and Future Research}

Improving the production by achieving the minimum manufacturing cost and minimum waste is of a great importance for organizations. JIT is practiced widely by today's organizations to minimize the costs and to have 
better response to the constantly changing demands. Reserving minimum work in process is aimed by JIT system. This research shows how the selection of the production control policy Kanban can result in significantly different levels of WIP and Lead Time. This research provides a systematic method to be used by intelligent expert systems is selecting the policies.

\subsection{Contribution}

Three aspects of contribution are identified for this research. These aspects are first theoretical, second methodological, and third practical.

The theoretical comparison enriches the JIT literature by indicating the significant difference in results based on production policy selection. This comparison is made for a comprehensive multi-level and multi-stage manufacturing line with variable demand controlled via different policies. Several measurement indicators are used by this research including WIP level, lost demand, lead time, and delay.

The proposed approach is a methodological contribution that connects the application of discrete event computer simulation and combining it with two fuzzy multi-criteria decision-making methods. This research proves the capability of this technique to improve the results of production control problems. Developing several models for production control policies by this research improves the current knowledge of manufacturing systems modeling. The proposed hybrid models are how various control systems can be developed based on common Kanban and ConWIP systems.

Presenting a real manufacturing line from auto-part industry, this study examines the application of this approach. The research introduces a systematic method to gather the data, design models and simulate the manufacturing lines. Computer simulation aids the manufacturer to observe the performance of intended production control policy ahead of implementation.

Finally this research introduces the importance of production control policies in reducing the costs and improving the profit for the organizations.

\subsection{Future Studies}

There are opportunities for future researches in this area due to several facts. First the high competition among manufacturers requires them to fortify their capabilities. The need of industry for knowledge creation in areas such as production control systems provides the demand for researches in this area.

Future researches can examine production control systems for different industries. While the principles of JIT originated from car manufacturing industry, the issue can be discussed in emerging industries.

\section{Declaration of Conflicting Interests}

The authors declared no potential conflicts of interest with respect to the research, authorship, and/or publication of this article.

\section{Funding}

This Paper research has been supported by a grant (No: 155147-2013) from the Natural Sciences and Engineering Research Council of Canada (NSERC).

\section{References}

Aguirre, A., Muller, E., Seffino, S., \& Méndez, C.A. (2008). Applying a Simulation-Based Tool to Productivity Management in an Automotive-Parts Industry. Proceedings of Winter Simulation Conference (1838-1846). Miami, FL. https://doi.org/10.1109/WSC.2008.4736273

Andijani, A.A. (1998). A multi-criterion approach for Kanban allocations. Omega International Journal of Management Science, 26(4), 483-493. https://doi.org/10.1016/S0305-0483(98)00004-8 
Ang, A. (2015). A performance comparison of single product kanban control systems. International Journal of Production Management and Engineering, 3(1), 57-74. https://doi.org/10.4995/ijpme.2015.3038

Ayag, Z. (2005). A Fuzzy AHP-Based Simulation Approach to Concept Evaluation in a NPD Environment. IIE Transactions, 37(9), 827-842. https://doi.org/10.1080/07408170590969852

Aydogan, E. (2012). Performance measurement model for Turkish aviation firms using the rough-AHP and TOPSIS methods under fuzzy environment. Expert Systems with Applications, 38(4), 3992-3998. https://doi.org/10.1016/j.eswa.2010.09.060

Ayhan, M.B. (2013). Fuzzy Topsis Application For Supplier Selection Problem. International Journal of Information, Business and Management, 5(2), 159-173.

Baykasoglu, A., Kaplanoglu, V., Durmusoglu, Z., \& Sahin, C. (2013). Integrating fuzzy DEMATEL and fuzzy hierarchical TOPSIS methods for truck selection. Expert Systems with Applications, 40(3), 899-907. https://doi.org/10.1016/j.eswa.2012.05.046

Chamodrakas, I., Batis, D., \& Martakos, D. (2010). Supplier selection in electronic marketplaces using satisficing and fuzzy AHP. Expert Systems with Applications, 37(1), 490-498. https:/ / doi.org/10.1016/j.eswa.2009.05.043

Chang, C.W., Horng, D.J., \& Lin, H.L. (2009). An IS quality measurement using gap and multicriteria decision making model: A case study for supply chain management system. Journal of Testing and Evaluation, 37(2), $181-188$.

Chen, S.J., \& Hwang, C.L. (1992). Fuz:y Multiple Attribute Decision Making: Methods and Applications. Berlin: SpringerVerlag. https://doi.org/10.1007/978-3-642-46768-4

Cochran, J.K., \& Kaylani, H.A. (2008). Optimal Design of a Hybrid Push/Pull Serial Manufacturing System with Multiple Part Types. International Journal of Production Research, 46 (4), 949-965.

https://doi.org/10.1080/00207540600905547

Farnoush, A., \& Wiktorsson, M. (2013). POLCA and CONWIP performance in a divergent production line: an automotive case study. Journal of Management Control, 24(2), 159-186. https://doi.org/10.1007/s00187-013-0177-z

Ferreira, L.P., Gómez, E.A., Lourido, G.C.P., Quintas, J.D., \& Tjahjono, B. (2012). Analysis and Optimisation of a Network of Closed-Loop Automobile Assembly Line Using Simulation. The International Journal of Advanced Manufacturing Technology, 59(1-4), 351-366. https://doi.org/10.1007/s00170-011-3502-4

Framinan, J.M., Ruiz-Usano, R., \& Leisten, R. (2001). Sequencing CONWIP Flow-Shops: Analysis and Heuristics. International Journal of Production Research, 39(12). 2735-2749. https://doi.org/10.1080/00207540110048972

Gilland, W.G. (2002). A simulation study comparing performance of CONWIP and bottleneck-based release rules. Production Planning \& Control, 13(2), 211-219. https://doi.org/10.1080/09537280110069784

Han, Y., Zhou, C., Bras, B., McGinnis, L., Carmichael, C., \& Newcomb, P.J. (2003). Paint Line Color Change Reduction in Automobile Assembly through Simulation. Winter Simulation Conference Proceedings, 2, 1204-1209. https://doi.org/10.1109/WSC.2003.1261551

Hou, T.H., \& Hu, W.C. (2011). An integrated MOGA approach to determine the Pareto-optimal kanban number and size for a JIT system. Expert Syst Appl, 38(5), 5912-5918. https://doi.org/10.1016/j.eswa.2010.11.032

Hwang, C.L., \& Yoon, K. (1981). Multiple Attributes Decision Making Methods and Applications. New York: Spring. https://doi.org/10.1007/978-3-642-48318-9

Kibira, D., \& McLean, C. (2002). Virtual Reality Simulation of a Mechanical Assembly Production Line. Winter Simulation Conference Proceedings 2, 1130-1137. https://doi.org/10.1109/WSC.2002.1166368

Kilic, H.S. (2012). Supplier Selection Application Based on a Fuzzy Multiple Criteria. Decision Making Methodology. AJIT-e: Online Academic Journal of Information Technology, 3(8), 7-18.

Khojasteh-Ghamari, Y. (2009). A performance comparison between Kanban and CONWIP controlled assembly systems. Journal of Intelligent Manufacturing, 20, 751. https://doi.org/10.1007/s10845-008-0174-5 
Khojasteh-Ghamari, Y. (2012). Developing a framework for performance analysis of a production process controlled by Kanban and CONWIP. Journal of Intelligent Manufacturing, 23, 61. https://doi.org/10.1007/s10845-0090338-y

Kouikoglou, V.S. (2000). Optimal Rate Allocation in Unreliable, Assembly/Disassembly Production Networks with Blocking. IEEE Transactions on Robotics and Automation, 16(4), 429-434. https://doi.org/10.1109/70.864238

Koulouriotis, D.E., Xanthopoulos, A.S., \& Tourassis, V.D. (2010). Simulation optimisation of pull control policies for serial manufacturing lines and assembly manufacturing systems using genetic algorithms. International Journal of Production Research, 48(10), 2887-2912. https://doi.org/10.1080/00207540802603759

Krafcik, J.F. (1988). Triumph of the lean production system. Sloan Management Review, 30(1), 41-52.

Lavoie, P., Gharbi, A., \& Kenné, J.P. (2010). A comparative study of pull control mechanisms for unreliable homogenous transfer lines. International Journal of Production Economy, 124(1), 241-251.

https://doi.org/10.1016/j.ijpe.2009.11.022

Little, J.D.C. (1961). A proof for the queuing formula: $\mathrm{L}=\lambda$ W. Operations research, 9(3), $383-387$. https://doi.org/10.1287/opre.9.3.383

Lu, R.F., \& Sundaram, S. (2002). Manufacturing Process Modeling of Boeing 747 Moving Line Concepts. Winter Simulation Conference Proceedings, 1, 1041-1045. https://doi.org/10.1109/WSC.2002.1172999

Manns, M., \& Elmaraghy, H.A. (2009). Inter-Arrival Time Patterns in Manufacturing Systems with Main and Side Loops. International Journal of Production Research, 47(10), 2721-2744. https:/ / doi.org/10.1080/00207540701691640

Marsh, R., Jonik, M., Lanham, J., Cheung, W.M., Newnes, L.B., \& Mileham, A.R. (2010). Modelling an Assembly Process Using a Close Coupled Generative Cost Model and a Discrete Event Simulation. International Journal of Computer Integrated Manufacturing, 23(3), 257-269. https:/ / doi.org/10.1080/09511920903529248

Mendes, A.R., Ramos, A.L., Simaria, A.S., \& Vilarinho, P.M. (2005). Combining Heuristic Procedures and Simulation Models for Balancing a PC Camera Assembly Line. Computers \& Industrial Engineering, 49(3), 413-431. https://doi.org/10.1016/j.cie.2005.07.003

Monden, Y. (2011). Toyota Production System: An Integrated Approach to Just-in-time. 4th edition. Boca Raton, FL: CRC Press.

Nadaban, S., Dzitac, S., \& Dzitac, I. (2016). Fuzzy TOPSIS. Procedia Computer Science, 91, $823-831$. https://doi.org/10.1016/j.procs.2016.07.088

Neira Dueñas, B., Lamas Rodríguez, A., Duro, R.J., \& García Del Valle, A. (2007). Macroevolutionary Algorithms in the Optimization of Industrial Plants, 4th IEEE Workshop on Intelligent Data Acquisition and Advanced Computing Systems: Technology and Applications, IDAACS, 255-260. Dortmund, September 6-8. https://doi.org/10.1109/IDAACS.2007.4488416

Ng, A.H.C., Bernedixen, J., \& Syberfeldt, A. (2012). A comparative study of production control mechanisms using simulation-based multiobjective optimization. Int J Prod Res, 50(2), 359-377. https://doi.org/10.1080/00207543.2010.538741

Ni, Y., \& Wang, Y. (2015). A double decoupling postponement approach for integrated mixed flow production systems. Kybernetes, 44 (5), 705-720. https://doi.org/10.1108/K-10-2014-0229

Ohno, T. (1988). Toyota Production System - Beyond large-scale production (1st ed.). Productivity Press.

Onut, S., Kara, S.S., \& Isik, E. (2009). Long Term Supplier Selection Using a Combined Fuzzy MCDM Approach: A Case Study for a Telecommunication Company. Expert Systems with Applications, 36(2), 3887-3895. https://doi.org/10.1016/j.eswa.2008.02.045

Opricovic, S. \& Tzeng, G.H. (2003). Compromise solution by MCDM methods: a comparative analysis of VIKOR and TOPSIS. European Journal of Operational Research, 156(2), 445-455. https://doi.org/10.1016/S0377$2217(03) 00020-1$ 
Otamendi, F.J. (2011). Screening Cell Designs Based on Synchronous Manufacturing. Proceedings of 25th European Conference on Modelling and Simulation (337-341), Krakow. https://doi.org/10.7148/2011-0337-0341

Pradhan, S., \& Damodaran, P. (2009). Performance Characterization of Complex Manufacturing Systems with General Distributions and Job Failures. European Journal of Operational Research, 197(2), 588-598.

https://doi.org/10.1016/j.ejor.2008.07.013

Prakash, J., \& Chin, J.F. (2014). Implementation of hybrid parallel Kanban-CONWIP system: a case study. Cogent Engineering, 1(1). https://doi.org/10.1080/23311916.2014.938922

Prajapat, N., \& Tiwari, A. (2017). A review of assembly optimization applications using discrete event simulation. International Journal of Computer Integrated Manufacturing, 30(2-3), 215-228.

https://doi.org/10.1080/0951192X.2016.1145812

Pourjavad, E., \& Shirouyehzad, H. (2014). Analyzing maintenance strategies by FANP considering RAM criteria: a case study. International Journal of Logistics Systems and Management, 18(3), 302-321.

https://doi.org/10.1504/IJLSM.2014.062818

Pourjavad, E., Shirouyehzad, H., \& Shahin, A. (2013). Selecting maintenance strategy in mining industry by analytic network process and TOPSIS. International Journal of Industrial and Systems Engineering, 15(2), 171-192. https://doi.org/10.1504/IJISE.2013.056095

Pourjavad, E., \& Peng, W. (2017). An Integrated MCDM approach for Risk Evaluation of New Product in Fuzzy Environment. International Journal of Product Development, 22(3), 165-188. https://doi.org/10.1504/IJPD.2017.087365

Saaty, T.L. (1980). The analytic hierarchy process. New York, NY: McGraw-Hill.

Sato, R., \& Praehofer, H. (1997). A Discrete Event Model of Business System - A Systems Theoretic Foundation for Information Systems Analysis: Part 1. IEEE Transactions on Systems, Man, and Cybernetics, 27(1), 1-10. https://doi.org/10.1109/3468.553213

Sato, R., \& Khojasteh-Ghamari, Y. (2012). An integrated framework for card-based production control systems. Journal of Intelligent Manufacturing, 23(3), 717-731. https://doi.org/10.1007/s10845-010-0421-4

Sharma, S., \& Agrawal, N. (2012). Application of fuzzy techniques in a multistage manufacturing system. International Journal of Advanced Manufacturing Technology, 60(1), 397-407. https:/ / doi.org/10.1007/s00170-011-3607-9

Sharma, S., \& Agrawalb, N. (2009). Selection of a pull production control policy under different demand situations for a manufacturing system by AHP-algorithm. Computers \& Operations Research, 36(5), 1622-1632. https://doi.org/10.1016/j.cor.2008.03.006

Slomp, J., Bokhorst, J.A.C., \& Germs, R. (2009). A lean production control system for high-variety/low-volume environments: a case study implementation. Production Planning and Control, 20(7), 586-595. https://doi.org/10.1080/09537280903086164

Spearman, M.L., Woodruff, D.L., \& Hopp, W. (1990). ConWlP: A pull alternative to kanban. International journal of Production Research, 28(5), 879-89. https://doi.org/10.1080/00207549008942761

Stratman, J.K., Roth, A.V., \& Gilland, W.G. (2004). The Deployment of Temporary Production Workers in Assembly Operations: A Case Study of the Hidden Costs of Learning and Forgetting. Journal of Operations Management, 21(6), 689-707. https://doi.org/10.1016/j.jom.2003.11.001

Thürer, M., Fernandes, N.O., Stevenson, M., \& Ting Qu, T. (2017). On the Backlog-Sequencing Decision for Extending the Applicability of ConWIP to High-Variety Contexts: An Assessment by Simulation. International Journal of Production Research, 55(16), 4695-4711. https://doi.org/10.1080/00207543.2017.1281462

Thürer, M., Stevenson, M., \& Protzman, C.W. (2016). Card-Based Production Control: a Review of the Control Mechanisms Underpinning Kanban, CONWIP, POLCA and COBACABANA Sytems. Production Planning \& Control, 27(14), 1143-1157. 
Torkabadi, A.M., \& Mayorga, R.V. (2017). Implementation of Just-In-Time Policies in Supply Chain Management. International Journal of Economics and Management Systems, 2, 315-320

Womack, J.P., Jones, D.T., \& Roos, D. (1990). The Machine That Changed the World. Simon \& Schuster Ltd.

Xanthopoulos, S., \& Koulouriotis, D.E. (2014). Multi-objective optimization of production control mechanisms for multi-stage serial manufacturing-inventory systems. International Journal of Advanced Manufufacturing Technology, 74(9-12), 1507-1519. https:// doi.org/10.1007/s00170-014-6052-8

Yang, H., Bukkapatnam, S.T.S., \& Barajas, L.G. (2013). Continuous Flow Modelling of Multistage Assembly Line System Dynamics. International Journal of Computer Integrated Manufacturing, 26(5), 401-411.

https://doi.org/10.1080/0951192X.2012.719085

Yang, T., Fu, H.P., \& Yang, K.Y. (2007). An evolutionary-simulation approach for the optimization of multi-constant work-in-process strategy: a case study. International Journal of Production Economics, 107(1), 104-114. https://doi.org/10.1016/j.ijpe.2006.02.014

Yu, Q., Duffy, V., McGinley, J., \& Rowland, Z. (2006). Productivity Simulation with Promodel for an Automotive Assembly Workstation Involving a Lift Assist Device. Proceedings of Winter Simulation Conference, 1935-1939, Monterey, CA. https://doi.org/10.1109/WSC.2006.322977

Zadeh, L.A. (1965). Fuzzy sets. Information Control, 8, 338-353. https://doi.org/10.1016/S0019-9958(65)90241-X

Zeng, X., Wong, W., \& Leung, S.Y. (2012). An Operator Allocation Optimization Model for Balancing Control of the Hybrid Assembly Lines Using Pareto Utility Discrete Differential Evolution Algorithm. Computers \& Operations Research, 39(5): 1145-1159. https://doi.org/10.1016/j.cor.2011.07.020

Zimmermann, H.J. (1996). Furay set theory and its applications. Massachusetts: Kluwer. https://doi.org/10.1007/978-94015-8702-0

Journal of Industrial Engineering and Management, 2018 (www.jiem.org)

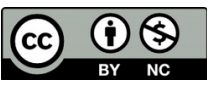

Article's contents are provided on an Attribution-Non Commercial 4.0 Creative commons International License. Readers are allowed to copy, distribute and communicate article's contents, provided the author's and Journal of Industrial Engineering and Management's names are included. It must not be used for commercial purposes. To see the complete license contents, please visit https://creativecommons.org/licenses/by-nc/4.0/. 